\title{
Percepções sobre os primeiros anos \\ do Projeto Autonomia e o neoliberalismo \\ no estado do Rio de Janeiro
}

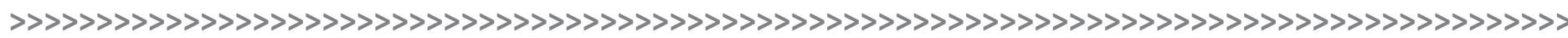

Fábio Souza Lima*

\section{Resumo:}

O presente artigo busca realizar um estudo sobre a implantação do Projeto Autonomia, dentro política educacional da Secretaria Estadual de Educação do Rio de Janeiro. Abordamos o contexto fluminense e nacional em que tal projeto foi implementado. A metodologia usada é da história oral, no que pesaram duas entrevistas realizadas com a mesma docente em tempos diferentes de sua experiência com o projeto. Estudaremos algumas ligações entre o Projeto Autonomia e as reformas educacionais brasileiras realizadas desde os anos 90, sob os auspícios da Conferência Mundial sobre Educação para Todos, realizada em Jomtien, na Tailândia.

\section{Palavras-Chave:}

Projeto Autonomia. Neoliberalismo. Conferência Mundial sobre Educação para Todos. Política educacional.

\begin{abstract}
:
This article aims to carry out a study about the implementation of the Autonomy Project, within the educational policy of the State Department of Education of Rio de Janeiro. We approach the Rio and national context in which such project was implemented. The methodology used is oral history, in which weighed two interviews with the same teacher at different times of their experience with the project. We will study some links between Projeto Autonomia and the Brazilian educational reforms carried out since the 1990s, under the auspices of the World Conference on Education for All held in Jomtien, Thailand.
\end{abstract}

\section{Keywords:}

Project Autonomy. Neoliberalism. World Conference on Education for All. Educational politics.

\section{Introdução}

O Projeto Autonomia foi implementado pela Secretaria Estadual de Educação do Rio de Janeiro num momento em que a ordem era a de informatização de tudo quanto possível dentro da Educação. A então Secretária de Educação, Tereza Porto (2008-2010), distribuiu computadores aos professores com internet $2 \mathrm{G}$ sob forma de empréstimo, iniciou a instalação de computadores alugados nas salas de aula e outorgou aos docentes a função de controlar digitalmente - além do já feito convencionalmente com os diários de papel - o calendário, a pauta, o lançamento de notas, além do próprio horário de trabalho, através de um sistema controlado e mantido por uma empresa privada terceirizada. Além

\footnotetext{
* > Professor do Instituto de Educação Carmela Dutra. Mestre e Doutor em Educação pelo Programa de Pós-Graduação em Educação da Universidade Federal do Rio de Janeiro (UFRJ). Pós-graduado em Políticas Públicas em Espaços Escolares pela Universidade Federal do Rio de Janeiro (UFRJ). Graduado em História pela Universidade Federal Fluminense (Licenciatura e Bacharelado) e em Filosofia pela Universidade Federal do Rio de Janeiro (Licenciatura e Bacharelado). E-mail: fabiosouzalima@gmail.com
} 
disso, as conexões entre os computadores que mantiveram o sistema funcionando e as conexões com a internet foram mantidas por outra empresa, a OI Corporação. No campo pedagógico, a Seeduc-RJ, seguindo a perspectiva do Governo Sérgio Cabral (2007-2014) de parceria público-privada, adotou também o Projeto Autonomia, da Fundação Roberto Marinho, cuja metodologia é o já conhecido Telecurso ${ }^{\circledR}$ - Telessalas ${ }^{\mathrm{TM}}$.

Nos últimos vinte anos, a expansão da metodologia do telecurso tornou-se tema controvertido no Brasil. Entre educadores e especialistas, existem aqueles que creem na associação deste fenômeno à ampliação de políticas neoliberais (LEHER, 2016), enquanto outros, afirmam que a prática da educação à distância pode trazer um grande benefício ao alunado. Diferenças essas que abordaremos um pouco mais a frente em nosso artigo. Contudo, dentro deste contexto, a proposta metodológica do Telecurso, organizada pela Fundação Roberto Marinho, base do Projeto Autonomia, enfatizou a exploração de recursos audiovisuais enquanto acumulava a algumas décadas inúmeras parcerias públicas e privadas. No Rio de Janeiro a implantação de tal metodologia junto à rede pública estadual fluminense não ocorreu sem acalorados debates no meio educacional, acontecidos a partir do ano de 2009. Segundo a Secretaria Estadual de Educação, a proposta ainda era corrigir a distorção causada pela repetência e minimizar as consequências resultantes desse atraso escolar, inclusive a evasão, utilizando-se do Projeto.

Coincidentemente ou não, há quase vinte anos atrás (1990) acontecia em Jomtien, na Tailândia, a Conferência Mundial sobre a Educação para Todos, onde foi produzida a Declaração Mundial sobre a Educação para Todos, financiada pelo Banco Mundial e reconhecidamente com diretrizes economicistas, destinadas aos Estados Nacionais (LIBÂNEO, 2012).

O educador José Carlos Libâneo (2012) afirma que tal Declaração, financiada pelo Banco Mundial, ofereceu as bases de uma educação voltada para as competências de uma vida em uma sociedade capitalista, onde todos aceitam suas posições sociais recebendo kit's de sobrevivência para isso. A escola dos ricos oferecia então uma educação assentada no conhecimento, na aprendizagem e na tecnologia, enquanto a escola dos pobres voltava-se para as missões sociais de assistência e apoio às crianças, oferecendo acolhimento às suas necessidades. A escola para os pobres, por não oferecer e aprofundar em aspectos cognitivos, acabava por figurar como um agente reprodutor da atual sociedade. Segundo o autor, não há, portanto, uma preocupação contestadora, mas, por outro lado, uma preocupação com a sociabilidade de aceitar as diferenças, ligada em manter a integração social, a convivência com os diferentes, o compartilhamento de culturas, a solidariedade entre as pessoas.

As análises de Torres e de Coraggio explicam a versão encolhida da Declaração de Jomtien adotada por boa parte dos países em vias de desenvolvimento. Têm-se, assim, traços básicos das políticas para a educação do Banco Mundial: a) reducionismo economicista, ou seja, definição de políticas e estratégias baseadas na análise econômica; b) o desenvolvimento socioeconômico necessita da redução da pobreza no mundo, por meio da prestação de serviços básicos aos pobres (saúde, educação, segurança etc.) como condição para torná-los mais aptos a participarem desse desenvolvimento; c) a educação escolar reduz-se a objetivos de aprendizagem observáveis, mediante formulação de padrões de rendimento (expressos em competências) como critérios da avaliação em escala; d) flexibilização no planejamento e na execução para os sistemas de ensino, mas centralização das formas de aplicação das avaliações (cujos resultados acabam por transformarem-se em mecanismos de controle do trabalho das escolas e dos professores) (LIBÂNEO, 2012, p. 19).

Apesar da superficial aparência de paz e tranquilidade em que se insere o Projeto que tem como valor a "integração social”, Ivani Pinto aponta que este é um momento 
de desconcentração de valores como Deus, Ser, Razão, Consciência, Produção Familiar, Estado, Revolução, diante da tecnologia. Tecnociência, que anuncia a chegada de um novo momento, instaurando dúvidas e novas opiniões sobre o papel da escola. Um momento de crise, de ruptura com um modelo, um momento de situação-limite onde os valores morais que permeiam o comportamento humano deveriam ser rediscutidos (PINTO, 2011). Uma nova época onde as discussões sobre qual o capital cultural que queremos que os jovens obtenham deveriam ser realizadas por toda sociedade.

\footnotetext{
O capital cultural - argumenta Bourdieu (1998) - que é legitimado nos currículos e utilizado na escola atua como filtro na reprodução dos saberes hegemônicos. A escola naturaliza estes saberes como se todos os alunos tivessem chances iguais de acesso a eles. Na verdade, existe uma diferença entre os que tiveram a oportunidade de conviver com estes saberes, por fazerem parte da cultura na qual eles se encontram inseridos, e os que não a tiveram, por se encontrarem inseridos em outra cultura. É esta diferença que provoca a exclusão, a repetência, juntamente com o prejuízo de outras dimensões, como a emocional, a social, dentre outras (PINTO, 2011).
}

Ora, concordamos com Ivani Pinto (2011) e Demerval Saviani (2005), que a escola e o currículo escolar apresentam-se como efeito de uma demanda construída pelos grupos sociais que controlam o capital cultual. Assim, é fácil identificar que as demandas por novos conteúdos e transformações na escola também são efeitos de uma construção realizada pelos mesmos grupos sociais que controlam o capital cultural.

\section{Os contornos da questão}

O Projeto Autonomia foi iniciado dentro da Secretaria Estadual de Educação no ano de 2009. Seu contexto segue uma série de características históricas que estão presentes não apenas no ambiente educacional, mas disseminado por todas as áreas em que o empresariado brasileiro está, de uma forma ou de outra, envolvido. O Projeto Autonomia é classificado como uma modalidade de ensino à distância, por ter a maior parte de seu processo de aprendizagem desenvolvido por meio de vídeos e apenas um professor responsável por estimular a produção intelectual dentro de sala. Apesar da expansão do Projeto e da sua metodologia nos últimos anos, isso não impediu que ele estivesse, ainda nos dias de hoje, em meio a uma discussão sobre a sua qualidade.

Contudo, o Projeto atende a Lei de Diretrizes e Bases da Educação, que no artigo 80 aponta que "O Poder Público incentivará o desenvolvimento e a veiculação de programas de ensino a distância, em todos os níveis e modalidades de ensino, e de educação continuada" (BRASIL, 2016). Ao estudar a legislação, podemos perceber que em variados pontos da LDBEN/96 há falta de especificação, e no caso do ensino à distância e uso da tecnologia, isso acaba por se tornar uma brecha onde surgem oportunidades para a atuação empresarial dentro da educação.

Em nosso país, o primeiro documento que refletiu a Declaração Mundial sobre a Educação para Todos, de 1990, foi o Plano Decenal de Educação para Todos (1993-2003) e posteriormente, a própria Lei de Diretrizes e Bases (Lei no 9.394/96). Em ambos os documentos, a influência do pensamento economicista e neoliberal do novo modelo educacional estava clara. De fato, segundo Libâneo (2012, p. 21), o Plano Decenal é praticamente uma reprodução da Declaração Mundial sobre a Educação para Todos. Por sua vez, sobre a LDB comentam Campos e Souza Júnior (2011). 
A promulgação da Lei 9.394/96 foi alvo de críticas e de análises de vários educadores, que pretendiam compreender seus significados e suas alterações para a educação brasileira. Dentre as críticas à LBD, destacam-se as de Severino (2003) e de Saviani (1996). Nas palavras do primeiro autor, a legislação não é inovadora, retoma princípios do neoliberalismo, o caráter ideológico não corresponde às reais necessidades, comprometida com a dicotomia público/privado, exigências exclusivas para o ensino público, o repasse de verbas é ambíguo, não consegue sustentar o princípio da gestão democrática, forte tendência centralizadora, a lei não decorre de um compromisso político mais amplo e profundo da sociedade, faz um discurso universal, mas garante apenas uma prática particularizada. Enquanto Saviani (1996) acredita que a LDB limitou-se ao ensino escolarizado, não corresponde a uma tomada de consciência dos problemas da educação nacional, não é fruto de um conhecimento da realidade nacional, não há uma teoria educacional norteadora. No que se refere à formação dos professores, Cury (2003) afirma que essa legislação não resolveu as questões relativas à formação desses profissionais.

Embora a palavra de ordem seja o uso da informática/tecnologia na Seeduc-RJ, a falta de especificações na sua utilização acaba por abrir mais possibilidades a um experimentalismo pedagógico que interfere diretamente na vida dos docentes e dos discentes. $\mathrm{O}$ educador Pedro Demo, que em seu livro A nova LDB: ranços e avanços, aponta que a falta de especificidade da LDB quanto ao uso de tecnologia (informática educativa), acaba por tornar esse tipo de ensino (à distância) um exemplo de aprendizagem de má qualidade, ou pior, que as lacunas deixadas pela LDB, tinham mesmo o intuito de oferecer "oportunidades" a serem aproveitadas pelas grandes redes de televisão (1997).

Todas as avaliações conhecidas mostram que a educação a distância tem sido um expediente muito pálido de aprendizagem. Apenas ver televisão, por mais atraentes que sejam os programas, não garante a aprendizagem, porque esta passa, em primeiríssimo lugar, pelo esforço reconstrutivo dos alunos. Assim, temos aí uma comprovação essencial da baixíssima utilidade da mera aula, ainda que dotada de todos os enfeites e efeitos especiais que a televisão pode inventar. Ruiu por terra a expectativa banalizante de que tal modalidade educacional viria facilitar a vida das pessoas, chegando-se ao exagero de que a própria distância teria efeito pedagógico (DEMO, 1997).

No primeiro ano de mandato, trançando um perfil de sua administração pública, o Governo Sérgio Cabral tentou implementar o primeiro concurso para o magistério que aconteceria sob o regime celetista, isto é, seria o primeiro concurso a submeter os professores à CLT (Consolidação das Leis do Trabalho), e não mais ao Estatuto do Servidor Público. No mesmo ano, por forte pressão popular e do sindicato da classe, seu intento malogrou. Contudo, ainda em seu primeiro mandato, com grande propaganda na imprensa, Cabral alugou computadores e aparelhos de ares-condicionados para colocar nas salas de aulas dos Colégios Estaduais. A despeito das denúncias de que os aparelhos não funcionavam, de que estariam parados, de que as escolas não teriam estrutura para recebê-los ou de que eles teriam sido alugados a valores mais altos do que seriam os valores de compra, $o$ governo recebeu forte apoio e promoção da imprensa. Muitos contratos foram firmados com empresas terceirizadas que ficaram responsáveis por setores da administração da secretaria dos colégios e pela manutenção dos computadores e ares-condicionados das unidades escolares.

Diante da crise política e de imagem ligada a denúncias de proximidade excessiva a empresários com interesses no Estado - que o atingiram em junho -, o governador do Rio, Sérgio Cabral Filho (PMDB), mais que dobrou as verbas oficiais destinadas ao setor de publicidade e imprensa em 2011. 
Em dois decretos publicados após as acusações, Cabral elevou de $\mathrm{R} \$ 55,7$ milhões para R\$120,7 milhões a autorização para gastos com Serviços de Comunicação e Divulgação da Subsecretaria de Comunicação e Divulgação - elevação de 116,75\%. Até ontem, foram empenhados $\mathrm{R}$ \$75,6 milhões e liquidados $\mathrm{R} \$ 67$ milhões. O governo nega relação desse aumento com a crise ${ }^{1}$.

Outros contratos foram firmados com as empresas privadas que ficaram responsáveis por fornecer sinal de internet para os colégios e professores. E no ano de 2009, aconteceu o que viria a se tornar símbolo da campanha de melhoria nas condições de trabalho dos professores, o Governador passou aos docentes computadores portáteis das empresas Positivo e CCE. Novamente houve denúncia. Desta vez, os computadores comprados no atacado, cerca de $31 \mathrm{mil} \mathrm{no} \mathrm{primeiro} \mathrm{lote} \mathrm{(70} \mathrm{mil} \mathrm{no} \mathrm{total),} \mathrm{teriam} \mathrm{sido} \mathrm{comprados} \mathrm{a} \mathrm{um}$ valor superior ao de varejo nas lojas de shoppings do Rio de Janeiro. Esses computadores, que não foram dados, mas emprestados sob a condição do professor continuar na rede de ensino, foram colocados pelos meios de comunicação de massa como se fosse o principal fator promotor do avanço pedagógico e tecnológico, ambos visando a melhoria da educação no Rio de Janeiro (SEEDUC, 2010).

Não obstante, apesar de todo o trabalho com tecnologia, em 2010, o Índice de Desenvolvimento da Educação Básica (IDEB), revelou que o ensino estadual do Rio de Janeiro é o segundo pior do país. Em um escalonamento feito pelo Índice, o Estado do Rio, com 2,8 em uma graduação que vai até 10, ficou com o penúltimo lugar entre as unidades da federação, apenas a frente do Piauí, uma das unidades mais pobres da federação (G1/ GLOBO, 2010).

Apesar da imprensa não comentar mais sobre o caso no início do ano de 2011, na época em que o índice foi divulgado, foi impossível conter a crise dentro do setor. Enquanto jornalistas especulavam insistentemente sobre a qualidade da formação dos professores, pressionando o Governo por resultados melhores, acadêmicos como o professor Doutor Roberto Leher, raramente ouvidos pelos meios de comunicação de massa, continuaram a apontar que é inadmissível, por exemplo, um sistema de educação que aprove alunos sem terem cumprido o currículo, com todas as disciplinas da grade.

De acordo com o SEPE - Sindicato Estadual de Profissionais de Educação do Rio de Janeiro -, de janeiro a junho de 2010, a rede estadual perdeu quase quatro professores por dia, sem contar com os que se aposentam, os que falecem ou que são demitidos, pois se esses fossem levados em consideração, o numero subiria para onze por dia. Anualmente o Estado tem realizado concursos para a admissão de professores. O maior deles, anunciado e realizado no ano de 2008, ofereceu 15 mil vagas, um concurso gigantesco até para o nível federal, maior ainda se considerarmos a situação do Estado do Rio de Janeiro. Nos dois anos seguintes as vagas foram preenchidas e criadas novamente. Ainda segundo o Sindicato e também nas palavras do Educador Nicolas Davies, professor da Universidade Federal Fluminense, vemos a seguinte constatação: “O professor não permanece na rede porque o salário é muito ruim. Eu mesmo fui professor durante nove anos, mas assim que pude, prestei concurso para a UFF". ${ }^{2}$

No ano de 2011, o Governador anunciou que os professores desviados de função, ou seja, aqueles que têm licenciatura mas decidiram trabalhar em funções administrativas, teriam que voltar à sala de aula. Aqueles que foram cedidos para outros órgãos, retornariam a sua unidade escolar para voltar a assumir turmas. Eram cerca de 2 mil professores que, mesmo sem querer, tiveram que voltar a dar aulas. E ainda, no mesmo ano, também foi anunciado que os professores das séries iniciais, chamados de PII, deveriam ser aproveitados nas salas do Ensino Médio. São professores que lecionam nas séries de alfabetização e que serão transformados em professores de disciplinas do Ensino Médio. As séries iniciais, que segundo a LDB são de responsabilidade dos municípios, serão agora,
1 > Jornal Estado de São Paulo. Disponível em: http://www.estadao.com.br/noticias/ nacional,apos-crise-cabral-dobra-gastoscom-publicidade,744338,0.htm. Acesso em: 19 set. 2012.

$2>$ DAVIES apud UOL Educação. Disponível em: http://educacao.uol.com.br/ noticias/2010/08/26/rede-estadual-do-rj -perde-quatro-professores-por-dia-baixo-salario-seria-motivo-da-desistencia.htm. Acesso em: 19 set. 2012. 
na prática, graças a política educacional do Governo, exclusividade dos municípios, e cerca de 22 mil professores, como anunciados nos jornais, deverão ser conduzidos às salas de aula dos últimos anos de formação da educação básica. Mas ainda assim, segundo as entidades da classe, faltavam professores.

Todos os anos, milhares de alunos se formam sem terem estudado disciplinas básicas como Física, Química, Filosofia, entre outras matérias. Mas a solução do Estado continuava sendo a mesma há anos; para corrigir o problema da falta de docentes, a invenção da sigla "SP" (Sem Professor) para poder aprovar ano após ano esses alunos. Em um Estado como o Rio de Janeiro, com variadas instituições públicas superiores, não há uma verdadeira falta de profissionais, mas uma desistência desses na profissão de professor. As condições de trabalho, a qualificação e os salários, com foco no professor, deveriam ser o foco de ação do Estado (MENDONÇA, 2010). Contudo, caso isso fosse feito, teríamos uma política pública que reforçaria a responsabilidade e a intervenção do Estado na Educação, o que seria mal visto pelas bases políticas neoliberais.

Torres (2001) esclarece em seu texto que, ao longo das avaliações e revisões da Declaração em conferências e reuniões subsequentes entre os organismos internacionais e os países envolvidos, a proposta original foi encolhida, e foi essa versão que acabou prevalecendo, com variações em cada país, na formulação das políticas educacionais. Tal encolhimento deu-se para adequar-se à visão economicista do Banco Mundial, o patrocinador das conferências mundiais. Desse modo, a visão ampliada de educação converteu-se em uma visão encolhida, ou seja: a) de educação para todos, para educação dos mais pobres; b) de necessidades básicas, para necessidades mínimas; c) da atenção à aprendizagem, para a melhoria e a avaliação dos resultados do rendimento escolar; d) da melhoria das condições de aprendizagem, para a melhoria das condições internas da instituição escolar (organização escolar).

Numa análise pedagógica dessas estratégias, verifica-se, tal como alerta Torres (2001), que as necessidades básicas de aprendizagem transformaram-se num "pacote restrito e elementar de destrezas úteis para a sobrevivência e para as necessidades imediatas e mais elementares das pessoas", bem próximas da ideia de que o papel da escola é prover conhecimentos ligados à realidade imediata do aluno, utilizáveis na vida prática (como acreditam, também, algumas concepções mais simplistas da ligação do ensino à vida cotidiana). Em síntese, a aprendizagem transforma-se numa mera necessidade natural, numa visão instrumental desprovida de seu caráter cognitivo, desvinculada do acesso a formas superiores de pensamento (TORRES apud LIBÂNEO, 2012).

\section{O Projeto Autonomia como solução de uma crise programada}

O significado do termo Autonomia se relaciona, em um primeiro momento, com a liberdade política de uma sociedade, capaz de governar-se por si mesma de forma independente e com autodeterminação. Porém, mais tarde, será com o desenvolvimento do iluminismo e da filosofia kantiana (KANT, 2000) que o termo autonomia ganhará contornos de caráter pessoal, individual. A palavra Autonomia tem sua origem na antiga Hélade. O adjetivo pronominal autos vem do grego "por si mesmo", "o mesmo", "ele mesmo" e no substantivo nomos, também de origem grega, que quer dizer "instituição", "lei", "convenção", "norma” ou "uso". Aliás, instituição, segundo Saviani (2005), entre as acepções existentes, também pode apresentar o significado de escola.

Historicamente, o conceito de autonomia nasce na cultura política da democracia grega para indicar as formas de governo autárquicas, e é somente a partir do humanismo individualista da Idade Moderna, que culmina na Aufklärung (Iluminismo) do século XVIII, que o conceito de autonomia se aplica ao indivíduo. Desde então, o indivíduo se torna um autêntico sujeito moral, titular de direitos e deveres correspondentes, e 
capaz de querer o Bem voluntária e racionalmente. A primeira formulação sistemática do conceito de autonomia, aplicado ao indivíduo, deve-se a Kant, para quem o sujeito moral em questão é a pessoa, isto é, o indivíduo racional e livre, e é por isso que a ética kantiana será conhecida como "racionalismo ético". Em Fundamentação da metafísica dos costumes (1785), Kant afirma que a lei moral autônoma é aquela que tem na "vontade boa" (das gute Wille) seu fundamento e legitimidade, sendo o único princípio fundamental (Kant utiliza o termo "supremo") da moralidade e, portanto, garantia da personalidade moral. Ela se contrapõe à heteronímia que é, propriamente, ausência de moralidade, pois estaria embasada na "vontade má" (das böse Wille) e na irracionalidade (CASTORIADIS apud SCHRAMM, 1998).

O pensador brasileiro Paulo Freire, consonante com as ideias apresentadas sobre o conceito de autonomia, em seu livro Pedagogia da Autonomia, motiva-se contra a perspectiva de que as pessoas devem se conformar com a sua posição social. Põe-se contra a ideia de que não deve ser dado aos jovens e adultos o conteúdo e a postura suficiente para o desenvolvimento de um pensamento crítico, capaz de intervir na sociedade em que vivemos. Coloca-se contra, ainda, aos que acreditam em uma educação técnica ou bancária, que visa incutir na cabeça dos discentes apenas o conteúdo necessário a uma vida submetida à Ordem Social estabelecida pelas elites sociais (FREIRE, 1996). O livro Pedagogia da Autonomia, do referido autor, nos apresenta um referencial que se relaciona com a definição da palavra autonomia e da proposta kantiana, quando aponta que os alunos devem ser encorajados a buscar e construir o saber, sendo a eles fornecida apenas a orientação para que esse processo ocorra naturalmente. Isto é, os alunos não devem estar passivos diante das informações que a eles chegam, pois o resultado seria o oposto do desenvolvimento crítico: a alienação ideológica.

Naturalmente, a ideologia, como propõem Marx e Engels (1987), funciona como um processo de submissão das ideias de um sujeito a outro sujeito. Quando este processo de submissão está completo, temos um sujeito alienado ao outro através das ideias. Trata-se então, para o desenvolvimento de nosso trabalho, importante que entendamos, mesmo que brevemente, o funcionamento de uma ideologia, já que como é colocado pela filósofa Marilena Chauí (1980), a educação e os meios de comunicação de massa são alguns dos principais disseminadores de ideias que atendem a determinados grupos sociais.

1. Embora a sociedade esteja dividida em classes, a dominação de uma classe sobre a outra, faz com que só as ideias da primeira sejam consideradas válidas, verdadeiras e racionais;

2. Para que isto ocorra, é preciso que os membros da sociedade não se percebam divididos em classes, mas se vejam como tendo certas características comuns a todos e que tornam as diferenças sociais algo derivado ou de menor importância; 3. Para que todos os membros se identifiquem com essas características supostamente comuns a todos, é preciso que sejam convertidas em ideias comuns a todos. Para que isso ocorra é preciso que a classe dominante, além de produzir suas próprias ideias, também possa distribuí-las, o que é feito, por exemplo, através da educação, da religião, dos costumes, dos meios de comunicação disponíveis;

4. Como tais ideias não exprimem a realidade real, mas representam a aparência social, as imagens das coisas e dos homens, é possível passar a considerá-las como independentes da realidade e, mais do que isto, inverter a relação fazendo com que a realidade concreta seja tida como a realização dessas ideias.

[...] Assim, a classe dominante (e sua aliada, a classe média) se divide em pensadores e não pensadores, ou em produtores ativos e consumidores passivos de ideias (CHAUÍ, 1980, p. 36). 
O Projeto Autonomia, como apontamos, é lançado dentro desse contexto de aumento da participação do empresariado em um governo de perfil administrativo neoliberal, de uma verdadeira evasão escolar de professores e de um discurso vagaroso de inserção de tecnologias novas (novas para Secretaria Estadual de Educação) na Educação do Estado do Rio de Janeiro. Percebemos então, em conformidade com o que apontamos aqui, que o colocado pelo filósofo Pierre Lévy (1999), em sua obra Cibercultura, fundamenta-se como pretexto para a utilização de um ensino quase completamente audiovisual: falta de professores e altos custos na formação tradicional.

[...] duas grandes reformas são necessárias nos sistemas de educação e formação. Em primeiro lugar, a aclimatação dos dispositivos e do espírito do EAD (ensino aberto e a distância) ao cotidiano e ao dia a dia da educação. A EAD explora certas técnicas de ensino a distância, incluindo as hipermídias, as redes de comunicação interativas e todas as tecnologias intelectuais da cibercultura. Mas o essencial se encontra em um novo estilo de pedagogia, que favorece ao mesmo tempo as aprendizagens personalizadas e a aprendizagem coletiva em rede. Nesse contexto, o professor é incentivado a tornar-se um animador da inteligência coletiva de seus grupos de alunos em vês de um fornecedor direto de conhecimentos (LÉVY, 1999, p. 157).

Assim, dentro desta já configurada situação educacional de evidente crise, a Secretaria de Educação apontou a expansão desse Projeto nos períodos de 2009, 2010 e 2011. Um projeto que, aplica a metodologia de uma empresa de comunicações de massa, prescinde da formação universitária dos professores, pois só utiliza um docente por turma e, ao colocar uma televisão e um DVD player dentro de sala de aula, atesta o discurso de modernização da educação.

Durante nosso período de pesquisa, escolhemos um colégio noturno e implementamos um questionário sobre a idade dos alunos da turma do Projeto Autonomia e alunos de uma turma do $1 .^{\circ}$ ano do ensino regular. Em ambas as turmas, $100 \%$ dos alunos apresentaram distorção da idade/série, que deveria ser de 15 anos. Os alunos, para realizarem inscrição no Projeto, até o ano em que esta pesquisa foi realizada, a faziam na secretaria do colégio como alunos regulares e depois eram escolhidos pelo professor que leciona no Projeto Autonomia. Questionamos sobre a evasão escolar, que apresentou os números aproximados para o Projeto e para o ensino regular.

Realizamos também duas entrevistas com um professor do Projeto, a primeira, logo no início do Projeto, e a segunda, quando o ano letivo já estava por terminar. Desde antes da publicação deste artigo, com receio de sofrer sansões da Seeduc-RJ, o docente pediu para não ser identificado. Procederemos, portanto, com respeito à vontade do profissional que nos concedeu este importante relato sobre a sua experiência docente, e o identificaremos pela sigla "V. A". Vejamos então, nas palavras do Professor V.A do Projeto Autonomia em sua $1^{\text {a }}$ entrevista, as condições das aulas:

VA - Junto com a Fundação Roberto Marinho, eles estão trabalhando aí... trazendo uma coleção de livros bem bacana, né. Então o material didático é muito bom, então há um investimento legal. O livro é dos alunos. Os alunos manuseiam, escrevem... Mas, assim como no Estado, depois, eles têm que devolver... Mas é legal porque eles têm um material muito rico em termos de conteúdo. Tem... a gente recebeu verba para comprar televisão, DVD, né. A gente recebe verba para o material todo específico do projeto. É claro, é bem aquém do que a gente gostaria ou do que a gente precisa, mas a gente vê que há um interesse do governo em investir em educação, principalmente desse pessoal que está fora, pra resgatar mesmo. E quanto a pessoal, a gente tem uma capacitação, uma vez a cada quatro meses, pra poder trabalhar as matérias, já que nós não somos específicos todas as matérias. Eu por exemplo, sou de educação física, tem que estudar matemática, tem que estudar física... 
Então eles proporcionam essa capacitação pra gente de quatro em quatro meses, pra poder ajudar. Tem supervisor, tem uma equipe multidisciplinar que ajuda a gente. FSL - E no final do ano você sai...

VA - Sim, após os cursos de capacitação e as aulas ministradas, a gente sai pós-graduado em Políticas Públicas (SOUZA LIMA, F. Projeto Autonomia - $1^{\text {a }}$ Entrevista. Maio de 2011).

Desta forma, como em toda prática capitalista, vê-se na crise do Sistema de Ensino, no que diz respeito a sua eficácia e produtividade, uma oportunidade de expansão dos serviços dados a competência da iniciativa privada. A falta de professores pode então ser resolvida com uma metodologia que exige apenas um professor por turma no Ensino Médio.

Considerando um curso de dezoito meses em que o docente recebe seis aulas de capacitação para lecionar todas as matérias do Ensino Médio. A referida capacitação, citada na entrevista, que acontece quadrimestralmente, dura cerca de quarenta horas, divididas pelos cinco dias de uma semana. Questionado sobre o funcionamento e sobre o conteúdo dessas capacitações, o entrevistado responde:

VA - Bom, as capacitações são específicas de cada disciplina, sempre com ênfase na metodologia do Telecurso, então, toda vez que a gente tem capacitação sobre as disciplinas de cada módulo, eles dão bastante ênfase na metodologia, sempre enfatizando os pontos básicos, na leitura de texto, na dinâmica de imagem... na forma como abordar o aluno, para que ele tenha esse conteúdo, na forma como abordar a disciplina, e sempre dando mais importância aos conteúdos que são básicos para que o aluno possa sair formado. Eles sempre dão esse adendo. Porque o livro, ele é bastante completo, mas pelo fato do curso ser bastante reduzido, nem sempre a gente vai conseguir abordar aquele conteúdo. Então eles explicam bastante que a gente, dentro das formações, tem que ter um olhar mais direcionado para o específico e imprescindível para cada disciplina.

FSL - Você falou que eles ensinam como abordar o conteúdo e a abordar a disciplina, mas e o conteúdo dentro da disciplina, você chega a ter aulas?

VA - Eles escolhem algumas aulas, que não... olha muito raramente... Posso falar isso, de verdade? ...muito raramente, muito raramente, a gente consegue ter algum profissional capacitado da área para poder ajudar. Quando existe no grupo algum professor específico da área, esse colega então nos dá uma força. Mas a Fundação Roberto Marinho, ela só manda capacitadores para poder nos ajudar com a metodologia. O tempo todo é a metodologia... a metodologia da Fundação. Não com o conteúdo. E o que eles fazem, eles levam duas ou três aulas que sejam chave. E a gente trabalha em cima dessas duas ou três tele-aulas. E aí ali dentro, dentro do que eles sugerem... "ah, hoje vamos trabalhar a tele-aula de número 24!". A gente vê aquela tele-aula e aí, no grupo, nós começamos a ter ideias de como aquilo poderia ser trabalhado. $\mathrm{Na}$ verdade, é o conteúdo confrontando o professor, né?! Como a gente pode trabalhar... e aí vão surgindo ideias... e daquelas três ou quatro aulas que nós fazemos ali, nós começamos a ter ideias do que fazer nas próximas. Mas muito raramente existe alguém específico para dar à gente ajuda nesse ponto. Tem que ser o professor versus o conteúdo.

FSL - Quanto tempo de antecedência você recebe essa capacitação para poder dar aula daquele conteúdo, daquele módulo?

VA - Normalmente a capacitação acaba na sexta e você tem que dar o conteúdo na segunda. O que não acontece, porque os livros acabam sendo entregues depois...

FSL - Depois de terminada a capacitação, você tem um órgão, ou um telefone, algum lugar que você possa tirar alguma dúvida sobre uma disciplina, por exemplo? 
VA - Olha, teoricamente, nós temos os nossos supervisores e uma equipe de orientação pedagógica, que deve nos ajudar com qualquer tipo de dúvida. A gente manda o e-mail e eles respondem para a gente. Ou mesmo, através de um grupo que a gente tem na internet e eles vão passando tele-aulas que já aconteceram em outros colégios e a gente pode utilizar.

FSL - Sobre os recursos audiovisuais, o Estado ou a Fundação dá suporte para o uso de algum outro tipo de tecnologia, fora a TV ou DVD?

VA - A verba que a gente recebe é para TV e DVD. Qualquer outro suporte, se a escola tiver condições de financiar... aí é por parte de cada UE, cada Unidade Escolar. Mas o Projeto Autonomia, viabiliza uma verba para ter televisão e DVD.

FSL - Os alunos têm acesso à internet?

VA - Por conta própria. Aqui não.

FSL - Têm acesso a redes sociais que estejam ligados ao Projeto Autonomia?

VA - Nós temos uma comunidade, dentro do Orkut, que eles acessam quando têm a possibilidade de estar com o computador... que não são todos... na verdade, de uma turma de 22 alunos frequentando, eu tenho uns 6 alunos que têm acesso a internet mais frequentemente. (SOUZA LIMA, F. Projeto Autonomia - 2a Entrevista. Dezembro de 2011).

Segundo Libâneo, as políticas de universalização do acesso ao ensino acabam por prejudicá-lo, uma vez que há maior preocupação com os números de acesso do que com a qualidade da aprendizagem.

Ocorre uma inversão das funções da escola: o direito ao conhecimento e à aprendizagem é substituído pelas aprendizagens mínimas para a sobrevivência. Isso pode explicar o descaso com os salários e com a formação de professores: para uma escola que requer apenas necessidades mínimas de aprendizagem, basta um professor que apreenda um kit de técnicas de sobrevivência docente (agora acompanhado dos pacotes de livros didáticos dos chamados sistemas de ensino) (LIBÂNEO, 2012, p. 23).

E após as seis capacitações, segundo o Estado, os professores estão tão bem preparados que além de lecionarem todas as disciplinas, também são considerados especialistas em Políticas Públicas. Segundo o professor V.A a Pós-Graduação lato sensu foi prometida aos docentes ao final da primeira turma formada. De fato, apesar da promessa, os professores não foram contemplados com certidão alguma.

Tomaz Tadeu Silva e Pablo Gentili (1996) explicam como a propaganda de uma crise e a proposta de sua resolução são apresentadas para a sociedade.

Segundo os neoliberais, esta crise se explica, em grande medida, pelo caráter estruturalmente ineficiente do Estado para gerenciar as políticas públicas. O clientelismo, a obsessão planificadora e os improdutivos, labirintos do burocratismo estatal explicam, sob a perspectiva neoliberal, a incapacidade que tiveram os governos para garantir a democratização da educação e, ao mesmo tempo, a eficiência produtiva da escola. A educação funciona mal porque foi malcriadamente peneirada pela política, porque foi profundamente estatizada. A ausência de um verdadeiro mercado educacional permite compreender a crise de qualidade que invade as instituições escolares.

Para dissolver a crise formada, o Governo do Rio de Janeiro iniciou o ano de 2011 com propostas já conhecidas dentro dos meios acadêmicos. Sua política educacional, seguindo a cartilha neoliberal conservadora, criou provas bimestrais que serão aplicadas 
pelo Estado para verificar e ranquear a aprendizagem dos alunos e a dedicação dos docentes. Estes últimos serão premiados segundo as notas dos alunos, de forma a se adequarem aos conteúdos específicos determinados pelos currículos mínimos estabelecidos pela Secretaria de Educação. Trata-se, como aponta os educadores Tomaz Tadeu Silva e Pablo Gentili, na obra Escola S.A.: quem ganha e quem perde no mercado educacional do neoliberalismo, da resolução dos problemas educacionais segundo o modelo neoliberal: princípios meritocráticos e competitivos; preocupação com produtividade e eficiência; subordinação às necessidades do mercado de trabalho e empregabilidade (SILVA; GENTILI, 1996).

É importante ressaltar que entendemos como empregabilidade as competências necessárias para buscar um emprego, neste caso, no mercado de trabalho. Como já citamos, um kit de sobrevivência e colocação dentro da sociedade. Nas palavras do professor V. A, a formação rápida acontece da seguinte forma:

\begin{abstract}
VA - O Projeto é que esses alunos tenham uma síntese do conteúdo que abrange todo o Ensino Médio, mas de uma forma bem resumida e em módulos. Mas como assim em módulos? Para esses alunos, a Fundação Roberto Marinho entende, já que é a proposta deles, que o conteúdo é muito pesado e extenso para que seja dado concomitantemente. Então eles fazem da seguinte forma: eles separam módulos, de alguns meses, e os alunos, nesses módulos, trabalharão determinados conteúdos específicos e que se entrelaçam para facilitar a interdisciplinaridade e de uma forma mais prática, mais concreta do que a linguagem simplesmente abstrata dos livros. Então o que acontece, $\mathrm{o}$ aluno vê, num período curto, somente três ou quatro disciplinas e a gente trabalha com vídeos; a educação é 70\% visual [...] (SOUZA LIMA, F. Projeto Autonomia - 1a Entrevista. Maio de 2011).
\end{abstract}

O Projeto Autonomia visa formar o aluno nos anos finais da educação básica (Ensino Médio) no prazo de um ano e meio. E embora o curso seja presencial, ele funciona necessariamente com vídeos, dentro de um modelo de educação à distância. Os alunos passam cerca de $70 \%$ de seu tempo sendo educados por vídeos e o restante em trabalhos de grupo com os colegas sobre os vídeos apresentados. No Projeto, apenas um professor é treinado para desenvolver as competências dos alunos em todas as disciplinas. Sem dúvida, resumir uma grade de cerca de dez professores em apenas um docente, além de capacitá-los com cursos que são ministrados de quatro em quatro meses, parece gerar, na linguagem neoliberal, lucro certo. Em entrevista, o professor do Projeto Autonomia ainda apontou que o salário do docente envolvido no Projeto é de duas vezes o salário de um professor regular do Estado, isto é, cerca de R\$2.000,00 atualmente (SOUZA LIMA, F.

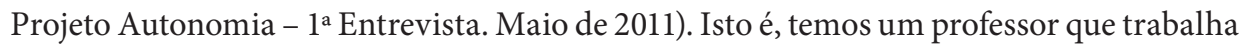
por 10 e ganha por dois, e ainda diminui o tempo de estadia do aluno na escola em $50 \%$, pois o Projeto, que cobre todo o Ensino Médio, dura apenas um ano e meio.

Vale ressaltar que este docente tem a responsabilidade de ministrar aulas durante todos os dias da semana e em todos os tempos. Considerando que no ensino regular uma turma teria algo entorno de dez professores que ministrariam aulas de duas a quatro horas na semana, o valor gasto com a educação desses alunos que cursam a educação básica regular seria muito maior. Além disso, os ganhos com a estrutura de ensino, como energia, limpeza, alimentação, água, etc., diminuem de acordo com o menor tempo em que o aluno fica na escola.

Essa "flexibilização" do currículo, visando o treinamento de competências voltadas a formação rápida é parte dos objetivos da classe social dominante para a manutenção da Ordem Social no país, pois atende a uma formação acrítica necessária à reprodução do atual estado da sociedade. Evidentemente, como já apontamos, para que uma ideologia funcione de forma eficaz, é imprescindível que ela apareça para toda sociedade como acessível e/ou necessária. Ou seja, aqueles que são dominados, as classes mais baixas, 
dependentes do ensino público, devem crer que a ideologia, as ideias disseminadas pelos grupos que controlam o capital cultural, não servem a ninguém em específico, devem crer que não beneficia nenhuma classe social, e que funciona como uma verdade incondicional, incontestável a todos. Destacamos, assim, as palavras do Doutor Roberto Leher (2010), professor da Faculdade de Educação da Universidade Federal do Rio de Janeiro:

Atualmente, contudo, em virtude da fragilidade da luta popular em prol da defesa da educação pública, as entidades empresariais reunidas no movimento Compromisso Todos pela Educação vêm buscando conformar toda a educação básica aos seus objetivos políticos ("governabilidade") e econômicos - difundindo um ethos adequado ao trabalho "flexível" e desregulamentado. Assim, estamos diante de uma falsa universalização que, no fundamental, mantém o apartheid educacional no país.

E claro, devemos ressaltar que é impossível realizar esse processo de convencimento e influência sem gastar muito dinheiro com a propaganda. Preferível é, e as elites sabem disso, possuir ou controlar os meios de comunicação de massa ou telas ao seu lado, por onde serão disseminadas ideias e valores concernentes ao modus vivendi de uma parcela da sociedade. Os valores são propagados pelas emissoras de televisão e rádio, e também através das escolas, como já vimos. Mesmo os professores, enquanto alunos universitários, sofrem a influência das ideias dentro da academia. E isso é normal, até entendermos que muitos projetos e bolsas universitárias são financiadas por instituições privadas nacionais e internacionais, que tolhem a independência intelectual dos muitos acadêmicos. Desta forma, são difundidos o pensamento e as práticas empresariais dentro da academia e para fora dela, quando os formandos são atirados no mercado de trabalho nas mais variadas funções sociais, notadamente, para os professores do ensino básico. O caso do Projeto Autonomia é ainda mais incisivo, pois uma empresa de televisão, rádio e jornal impresso tornou-se responsável pelo currículo e pelo método aplicado na aprendizagem e na construção do saber do jovem nos 70\% do tempo em que ele está na escola.

Leher afirma ainda que a adoção de escolas por empresas privadas é justamente o que defendem os membros do Compromisso Todos pela Educação. Para eles, a meta "é transformar cada escola em uma ilha cercada de prepostos empresariais de todos os lados" (2010, p. 11).

No caso da Fundação Roberto Marinho, ela possui uma série de projetos voltados para a educação, dentre eles o Telecurso TEC, Aprendiz Legal, Olá Turista e o Projeto Autonomia. Em todos os exemplos, a Fundação aplica a metodologia que se tornou uma marca registrada: o Telecurso/Telessala. Seus principais parceiros são: Federação das Indústrias do Estado de São Paulo (FIESP), Serviço Nacional de Aprendizagem Industrial (SENAI), Serviço Social da Indústria (SESI) e agora, os Estados, notadamente o Estado do Rio de Janeiro, onde fica a sede da Fundação e das Organizações Globo.

Contudo, coroando as relações públicas estaduais com setores do capital privado e o futuro educacional sombrio que se acerca do Estado do Rio de Janeiro, ao final do ano letivo de 2012, os professores da rede estadual ainda foram surpreendidos pela notícia de que seriam observados em suas aulas por agentes enviados pelo Banco Mundial.

3 > Disponível em: http://oglobo.globo. com/educacao/desempenho-de-professores-da-rede-estadual-do-rio-sera-monitorado-6446886\#ixzz2AKUCvtNX. Acesso em: 25 out. 2012.

\footnotetext{
- Os observadores que vamos treinar ficarão no fundo da sala e, seguindo um método padronizado adotado nos Estados Unidos, farão anotações sobre os materiais que os professores usam, as atividades que promovem e o grau de envolvimento dos alunos - explicou a economista-chefe do Banco Mundial para Educação na América Latina e na região do Caribe, Barbara Bruns, em uma das mesas do Global Economic Symposium, que aconteceu nesta semana no Rio.

Segundo Barbara, a indústria da educação é a única em que os "operários" (professores) não têm sua performance avaliada de forma direta e objetiva em busca de uma otimização do tempo. ${ }^{3}$
} 


\section{Conclusão}

O termo autonomia, necessariamente leva à produção de conhecimentos que partem de um esforço próprio, individual. O aluno como entidade, que com esforço próprio requer se tornar autônomo, deve desenvolver a capacidade subjacente de construção de saberes que propiciarão a sua relativa independência no meio em que habita e de outras pessoas. Dentro desta ideia de emancipação moral e intelectual - e podemos incluir também como desejo de todos, material -, segundo Kant (2000), o discente alcança a responsabilidade de seus direitos e deveres correspondentes, sendo capaz de discernir e escolher racionalmente.

Identificamos em contrário aquilo que é mais preterido dentro da noção de autonomia. Justamente o que o pensador brasileiro Paulo Freire (1996) afirma ser a educação bancária. Numa educação onde diariamente os alunos do Projeto Autonomia estão submetidos à passividade de assistir pela maior parte do tempo em que estão em sala de aula vídeos idealizados de situações cotidianas que não necessariamente correspondem às suas. $\mathrm{O}$ Telecurso, antigo Telecurso $2^{\circ} \mathrm{Grau}$, frequentemente leva aos alunos situações de empregos em fábricas e indústrias de todo tipo, com personagens ligados às linhas de produção, com dúvidas e questionamentos que pouco levam o espectador passivo além da relação patrão/ empregado. Junto a esse trabalho, as atividades em sala de aula que acontecem sempre com variados componentes, propõem um pensamento de grupo, comum, base do que é a alienação intelectual.

As implantações de projetos que estão tão aquém das fórmulas propostas pelos filósofos, acadêmicos e outros pensadores da educação só poderiam ser realizadas em uma situação considerada de exceção conjuntural, isto é, em um momento passageiro, quando administração do "remédio adequado", feito por autoridades (governantes e respectivos secretários), resolveria o problema visando um próximo passo. Mas, é desta forma que se revela hoje a falta de especificidade na legislação educacional que trata do uso de tecnologias educacionais, e é dela que aparece a oportunidade para a infiltração de empresas privadas e entes políticos que veem como negócio a Educação. De fato, o aluguel de equipamentos e a compra de outros movimentou muitos dos valores transferidos da União para o Estado na forma de verbas direcionadas à Educação. E ainda, a falta de profissionais de ensino dentro das salas de aula e os péssimos resultados no Índice de Educação Básica de 2010, ofereceram o pretexto necessário para a ampliação do Projeto Autonomia.

Tivemos como resultado o fato de que a formação profissional de cada docente, especialista em sua área de estudo, foi completamente suprimida em função da colocação de apenas um profissional responsável por coordenar os trabalhos de grupo e responder as possíveis dúvidas existentes ao final de cada apresentação de vídeo. O uso da televisão e do DVD aliados ao programa audiovisual da Fundação Roberto Marinho passaram a formar adultos no Ensino Médio oficialmente dentro das salas de aula do Estado do Rio de Janeiro do novo Ensino Médio. Um método de educação que anteriormente era usado como exceção por meio da tevê aberta para o operariado adulto que demonstrava vontade de continuar seus estudos até o final do Ensino Médio se generalizou como método e prática de ensino público.

O Projeto Autonomia iniciou no Estado em 2009, mesmo sem participação da sociedade e diálogo com os professores. Muito menos a formação básica de equipes multidisciplinares. Segundo a Secretaria de Educação, o Projeto segue em expansão pelos anos consecutivos de 2009, 2010, 2011 e atendeu, somente no ano passado, 500 turmas, com cerca de 20.700 alunos no total. E segundo os professores que nele atuam, o Projeto tornou-se a "menina dos olhos" do Estado.

Consonante com os pensamentos do Dr. Leher (2010) quando aponta que essa universalização da educação é falsa e mantém o apartheid social brasileiro, acreditamos que o Projeto Autonomia não torna qualquer aluno autônomo, mas pelo contrário, torna-o intelectualmente dependente, assegurando a manutenção de uma Ordem Social que tem como propriedade a exploração de algumas classes por outra classe.

Contudo, sobre a qualidade da educação oferecida pelo ensino formal, isto é, oficial, intencional, organizado por normas e de responsabilidade do Estado, gostaríamos de trazer 
ainda uma citação do Professor José Carlos Libâneo, que em seu livro Democratização da escola-pública: a pedagogia crítico-social dos conteúdos (1985), afirma:

[...] educar (em latim, educare) é conduzir de um estado a outro, é modificar numa certa direção o que é suscetível de educação. $\mathrm{O}$ ato pedagógico pode, então, ser definido como uma atividade sistemática de interação entre seres sociais, tanto no nível do intrapessoal como no nível da influência do meio, interação essa que se configura numa ação exercida sobre sujeitos ou grupos de sujeitos visando provocar neles mudanças tão eficazes que os tornem elementos ativos desta própria ação exercida. Presume-se, aí, a interligação no ato pedagógico de três componentes: um agente (alguém, um grupo, um meio social etc.), uma mensagem transmitida (conteúdos, métodos, automatismos, habilidades etc.) e um educando (aluno, grupos de alunos, uma geração etc.) (LIBÂNEO, 1985, p. 97).

No decorrer de nosso estudo, abordamos a afirmação colocada por Libâneo sobre as mudanças causadas nos educandos, que de tão eficazes, podem fazê-los realmente elementos ativos da própria ação exercida por eles. E então nos questionamos sobre que tipo de ser humano é formado a partir da educação exposta pelo Projeto Autonomia? Alunos sem professores especializados; estes, capacitados por apenas alguns meses, em detrimento dos anos em que os profissionais passam aprendendo a processar os conteúdos e a redistribuí-los de forma a assegurar o desenvolvimento crítico e a buscar nossos saberes.

Não é apenas a forma diferenciada de mediação do currículo proposto por uma empresa privada que ocasiona queda na qualidade de aprendizagem do público participante, mas também a própria qualidade do conteúdo do currículo, que mesmo em um pequeno prazo, não aborda de forma intensa os assuntos tratados no ensino regular. Esses discentes ainda são alijados de todas as possibilidades em que a tecnologia pode oferecer em um curso com verdadeiras preocupações de um Ensino à Distância. O uso da tecnologia para construção de novos saberes em redes sociais, a possibilidade de construção e publicação para a construção de novos saberes em rede não é a realidade do Projeto Autonomia. Vemos apenas alunos compelidos a escrever trabalhos de grupos, com pensamentos de grupos e sem a profundidade que caracteriza o termo Crítica.

Crítica e Autonomia são dois dos termos que estiveram presentes durante todo o nosso trabalho. Isto porque o primeiro, que significa analisar, ir à raiz do problema para poder conhecê-lo, dividir o objeto para melhor estudá-lo, e então, emitir um juízo de valor. O segundo significa basicamente ter um sujeito capaz de se arvorar titular de direitos e deveres. Um responsável e maduro cidadão, com a capacidade racional de buscar voluntariamente pelo bem individual e comum.

Para sociedade do conhecimento e do futuro, seriam esses indivíduos transformadores, como é a característica de entidades críticas ou seriam reprodutores passivos de uma Ordem Social que já existe? Bom, nas palavras de Paulo Freire, o qual trouxemos como citação inicial para orientação desse estudo, realizamos nosso pensamento de conclusão: “[...] o saber-fazer da auto reflexão crítica e o saber-ser da sabedoria exercitados, permanentemente, podem nos ajudar a fazer a necessária leitura crítica das verdadeiras causas da degradação humana e da razão de ser do discurso fatalista da globalização" (FREIRE, 1996, p. 5).

\section{Referências}

BRASIL. Lei no 9.394 de 20 de dezembro de 1996. Estabelece as diretrizes e bases da educação nacional. Brasília, DF: Casa Civil, 1996. Disponível em: http://www.planalto.gov.br/Ccivil_03/leis/ L9394.htm. Acesso em: 19 de fev. 2019. 
CAMPOS, Fernanda Araujo; SOUZA JÚNIOR, Hormindo. Políticas Públicas para a formação de professores: desafios atuais. Trabalho e Educação, Belo Horizonte, v. 20, n. 1, p. 33-46, jan./abr. 2011.

CHAUÍ, Marilena. O que é Ideologia. São Paulo: Editora Brasiliense, 1980.

DEMO, Pedro. A nova LDB: ranços e avanços. Campinas: Papirus, 1997.

FREIRE, Paulo. Pedagogia da Autonomia. Rio de Janeiro: Paz e Terra, 1996.

G1/GLOBO. Ensino Médio do Rio tem o segundo pior desempenho do país no Ideb. G1/GLOBO, Rio de Janeiro, 5 set. 2010. Disponível em: http://g1.globo.com/rio-de-janeiro/noticia/2010/07/ensinomedio-do-rio-tem-o-segundo-pior-desempenho-do-pais-no-ideb.html. Acesso em: 19 fev. 2019.

KANT, Immanuel. Crítica da Razão Pura. São Paulo: Nova Cultural, 2000. (Coleção dos Pensadores).

LEHER, Roberto. A luta pela educação pública tem de estar inscrita nas lutas contra o capitalismo dependente! Jornal dos economistas, órgão oficial do CORECON-RJ e do SINDECON-RJ, Rio de Janeiro, n. 253, p. 9-11, 2010.

LEHER, Roberto. Luta de classes e mercantilização da educação brasileira. In: INTERNATIONAL CONFERENCE STRIKES AND SOCIAL CONFLICTS: COMBINED HISTORICAL APPROACHES TO CONFLICT, 3., 2016, Barcelona. Proceedings [...]. Barcelona: Universitat Autònoma de Barcelona, 2016. p. 959-971.

LÉVY, Pierre. Cibercultura. São Paulo: Editora 34, 1999.

LIBÂNEO, José Carlos. Democratização da escola pública: a pedagogia crítico-social dos conteúdos. São Paulo: Loyola, 1985.

LIBÂNEO, José Carlos. O dualismo perverso da escola pública brasileira: escola do conhecimento para os ricos, escola do acolhimento social para os pobres. Educação e Pesquisa, São Paulo, v. 38, n. 1, p. 13-28, 2012.

MARX, Karl; ENGELS, Friedrich. Ideologia alemã. São Paulo: Editora Hucitec, 1987.

MENDONÇA, Ana Waleska. A Tragédia do Ensino público no Rio de Janeiro. Jornal dos economistas, órgão oficial do CORECON-RJ e do SINDECON-RJ, Rio de Janeiro, n. 253, p. 12-13, 2010.

PINTO, Ivany. A pós-modernidade: uma escuta sobre a nova cultura da aprendizagem na escola. Cadernos de Educação, Revista da Faculdade de Educação da UFPel, Pelotas, n. 38, p. 315-333, jan./abr. 2011.

SAVIANI, Dermeval. Instituições Escolares: conceito, história, historiografia e práticas. Cadernos de História da Educação: revista da Universidade Federal de Uberlândia, Uberlândia, n. 4, jan./dez. 2005.

SCHRAMM, Fermin Roland. A autonomia difícil. Bioética, Brasília, DF, v. 6, n. 1, p. 27-37, 1998.

SILVA, Tomaz Tadeu da; GENTILI, Pablo. Escola S.A.: quem ganha e quem perde no mercado educacional do neoliberalismo. Brasília, DF: CNTE, 1996.

\section{Sites}

" http://educacao.uol.com.br/ultnot/2010/08/26/rede-estadual-do-rj-perde-quatro -professores-por-dia-baixo-salario-seria-motivo-da-desistencia.jhtm

" http://portal.cederj.edu.br/fundacao/

»http://www.novotelecurso.org.br

" http://oglobo.globo.com

" http://www.projetossocio-culturais.blogspot.com/

» http://www.todospelaeducacao.org.br/comunicacao-e-midia/educacao -na-midia/12823/opiniao-como-lidar-com-o-fracasso-da-escola

» www.educacao.rj.gov.br/

"www.mec.gov.br/

»http://www.estadao.com.br/

»https://g1.globo.com/ 